\title{
Chesed Children's Clinic: A non- profit, paediatric primary care outreach clinic in the Eastern Cape created by junior doctors and volunteers
}

To the Editor: Mzamomhle in the Eastern Cape is an impoverished, peri-urban informal settlement of approximately 12000 people living in 3100 shacks. ${ }^{[1]}$ These dwellings have no running water, electricity or ablution facilities. Healthcare is provided by a single nurse-run primary care day-clinic. The hospital housing the majority of paediatric beds is about $40 \mathrm{~km}$ away, and there is no formal public transport or railway link between Mzamomhle and the hospital.

In response to health challenges faced by this community, a group of junior health professionals and volunteers formed a multidisciplinary non-governmental organisation (NGO) with the aim of improving paediatric health delivery to them. Since September 2011, the group has run a paediatric outreach clinic named the Chesed Children's Clinic, which has been operating on alternate Sundays from a former USAID clinic site adjacent to Mzamomhle. The clinic is entirely volunteer-run and is managed similarly to the University of Cape Town's SHAWCO clinics. ${ }^{[2]}$ Funds are procured through the generosity of donors. In the clinic, bio-psychosocial healthcare is practised. In addition to medical care, play-group therapy, counseling and pastoral care, team sports as well as arts and crafts workshops are offered.

Children are seen by volunteer doctors in private consultation rooms and are dispensed medication from the clinic's primary care pharmacy, as required. Those needing hospitalisation are transferred to local referral hospitals through partnership with a local advanced paramedic who is actively involved in the management of the clinic.

Although the clinic is still in its infancy, it is steadily growing. Plans exist for opening hours to be extended to every weekend.

We present our positive experience as a motivation for other junior health professionals to become involved in local community healthcare outside their normal working lives. All it takes is a dedicated team of friends with a united vision and enduring plans. The legal aspects of starting a health NGO can be obtained from the Department of Health and the Department of Social Development. We hope that our experience will influence others to embark on 
similar projects. More information on the clinic can be obtained from: chesedclinic@gmail.com.

\section{David M Favara}

East London Hospital Complex, East London, South Africa

(currently: Nuffield Department of Surgical Sciences, and Balliol College, University of Oxford, Oxford, UK)

david.favara@balliol.ox.ac.uk

\section{Lara Makin}

General practitioner, Gonubie, East London, South Africa

Buffalo City Metropolitan Municipality. Integrated Development Plan 2012/2013 Review. November 2012. http://www.buffalocity.gov.za/municipality/keydocs/draft_intergr_dev_201213.pdf (accessed 20 ary 2013)

2. Favara DM, Mendelsohn SC. The Students' Health and Welfare Centres Organisation (SHAWCO) of the University of Cape Town: A review of the past 69 years. S Afr Med J 2012;102(6):400-402.

S Afr Med J 2013;103(6):356-357. DOI:10.7196/SAMJ.6867 